\title{
El papel de los inhibidores del sistema renina- angiotensina-aldosterona en el desarrollo y evolución de la Covid-19
}

\section{Role of renin-angiotensin-aldosterone system inhibitors in the development and evolution of Covid-19}

Dado que estamos en una nueva ola de la Covid-19, y aún no se dispone de medidas de prevención eficaces, se requieren con urgencia encontrar estrategias para limitar la infectividad viral y la gravedad de la enfermedad.

El sistema renina angiotensina aldosterona (SRAA) es el principal regulador del volumen plasmático en mamíferos, manteniendo la homeostasis cardiovascular e hidrosalina; cumple un rol protector y adaptativo en situaciones de riesgo para nuestro organismo como la hipotensión, pérdidas de sodio o agua, y su desregulación tiene implicancias en el desarrollo de hipertensión y enfermedades cardiovasculares y renales ${ }^{(1)}$.

La activación de la vía clásica de la enzima convertidora de angiotensina (ECA), conlleva a la producción de angiotensina II (AII), que es una sustancia que posee potente efecto vasoconstrictor e inflamatorio; esta es la vía que todos conocemos. Sin embargo, existe una vía no clásica, que genera angiotensina 1-7, mediante clivaje de angiotensina I, que es contra reguladora de la AII (2); esto se genera por una variante de ECA, denominada ECA2, enzima identificada simultáneamente por Donoghue y Tipnis en el año $2000^{(3,4)}$.

Se ha comprobado que la ECA2 actúa como receptor del virus SARS-CoV-2, y de otros Coronavirus, y por lo tanto, es esencial para la infectividad viral y la entrada a las células ${ }^{(5)}$. Por ello, es necesario conocer los efectos que tendrían los IECA, ARAII e inhibidores de aldosterona en la infección por el virus SARS-CoV-2.

Muchos pacientes con hipertensión arterial, enfermedad renal o cardíaca, reciben inhibidores de la enzima convertidora de angiotensina (IECA), antagonistas de receptores de angiotensina II (ARAII) o inhibidores de la aldosterona, como parte de su terapia.

La preocupación sobre si los ARAII y los IECA pueden tener efectos nocivos sobre la morbilidad y la mortalidad de los pacientes con la Covid-19 se basa en la evidencia de una regulación positiva de ECA2 en estudios en animales con ARAII y IECA, pero utilizando dosis relativamente altas ${ }^{\left({ }^{(}\right)}$. Sin embargo, existen pocos estudios en humanos sobre los efectos de la inhibición del SRAA sobre la expresión de ACE2. En un estudio, la administración intravenosa de IECA en pacientes con enfermedad de las arterias coronarias no influyó en la producción de angiotensina 1-7; este hallazgo cuestiona que los IECA tengan algún efecto directo sobre el metabolismo de la angiotensina II vía ECA2 ${ }^{(7)}$. En otro estudio, en pacientes con hipertensión, los niveles de angiotensina 1-7 al parecer no se afectaron después del tratamiento inicial con captopril; sin embargo, con la terapia con captopril durante 6 meses, los niveles de angiotensina $1-7$, aumentaron ${ }^{(8)}$.

En un estudio se compararon las probabilidades de una prueba positiva para Covid-19 o el riesgo de Covid-19 grave entre los pacientes que dieron positivo, en personas que recibían cinco clases de medicamentos antihipertensivos: IECA, ARAII, $\beta$-bloqueadores, bloqueadores de canales de calcio y tiazidas; no se encontró aumento de la probabilidad o del riesgo de Covid-19 asociado con algún tipo de terapia antihipertensiva ${ }^{(9)}$. En un estudio caso-control, no se encontró evidencia que los IECA o ARAII afectaron el riesgo de Covid-19 ${ }^{(10)}$.

Es difícil predecir una medida terapéutica ideal para prevenir la Covid-19 o la mortalidad, basada en la modulación de la ECA2, ya que una reducción de la ECA2 en los sitios críticos para la entrada del virus en el cuerpo como la 
nariz, los pulmones y el tracto gastrointestinal podría limitar la infectividad, pero a su vez, en los órganos infectados se reduciría la generación de angiotensina 1-7, y por lo tanto, se favorecería la gravedad de la enfermedad, al no contar con el efecto protector de la angiotensina 1-7.

Actualmente, no se dispone de mediciones de los niveles de AII o aldosterona en pacientes con la Covid-19. Sin embargo, en un estudio de pacientes infectados con SARS-CoV-2 en China, se encontró una alta frecuencia de hipokalemia con potasio urinario incrementado y alcalosis metabólica, sugiriendo hiperaldosteronismo ${ }^{(11)}$.

De hecho, la espironolactona ha sido propuesta como fármaco para dar protección contra la Covid-19. La evidencia permite predecir que las reducciones del receptor de proteasa transmembrana serina tipo 2 (TMPRSS2), furina y plasmina y los aumentos de la proteasa nexina 1 (PN1), deberían producir beneficios contra la Covid-19. El virus requiere del procesamiento proteolítico de su proteína spike por el TMPRSS2 para permitir la unión a la ECA2 celular. La furina y la plasmina también procesan la proteína spike. El TMPRSS2 contiene un promotor de andrógenos, y puede estar regulado negativamente por la acción anti androgénica de la espironolactona; mientras que la furina y la plasmina son inhibidas por la PN1, cuya producción es estimulada por la angiotensina II y disminuida por la aldosterona. Es de suponer entonces que la espironolactona debería producir disminución de la furina y plasmina ${ }^{(12)}$. Esto último, requiere de investigación directa..

Juan Miyahira ${ }^{1, a, b}$

\section{REFERENCIAS BIBLIOGRÁFICAS}

1. Sparks M, Crowley S, Gurley S, et al. Classical renin-angiotensin system in kidney physiology. Compr Physiol. 2014; 4:1201-28.

2. Ferrario C, Chappell M, Tallant A, et al. Counterregulatory actions of angiotensin-(1-7). Hypertension. 1997; 30:535-41.

3. Donoghue M, Hsieh, Baronas E, et al. A novel angiotensin-converting enzyme related carboxypeptidase (ACE2) converts angiotensin I to angiotensin 1-9. Circ Res. 2000:87:e1-e9.

4. Tipnis SR, Hooper NM, Hyde R, et al. A human homolog of angiotensin-converting enzyme. Cloning and functional expression as a captopril-insentitive carboxypeptidase. J Biol Chem. 2000; 275(43):3323843.

5. Wan Y, Shang J, Graham R, Baric RS, Li F. Receptor recognition by novel coronavirus from Wuhan: An analysis based on decade-long structural studies of SARS coronavirus. J Virol. 2020; 94:e00127-20, http://dx.doi.org/10.1128/JVI.00127-20.

6. Soler MJ, Barrios C, Oliva R, Batlle D. Pharmacologic modulation of ACE2 expression. Curr Hypertens Rep $2008 ; 10: 410-4$.
7. Campbell DJ, Zeitz CJ, Esler MD, Horowitz JD. Evidence against a major role for angiotensin converting enzyme-related carboxypeptidase (ACE2) in angiotensin peptide metabolism in the human coronary circulation. J Hypertens 2004; 22:1971-6.

8. Luque M, Martin P, Martell N, Fernandez C, Brosnihan KB, Ferrario CM. Effects of captopril related to increased levels of prostacyclin and angiotensin-(1-7) in essential hypertension. J Hypertens 1996; 14:799-805.

9. Reynolds HR, Adhikari S, Pulgarin C, et al. ReninAngiotensin-Aldosterone System Inhibitors and Risk of Covid-19. N Engl J Med 2020; 382:2441-8. DOI: 10.1056/NEJMoa2008975

10. Mancia G, Rea F, Ludergnani M, et al. ReninAngiotensin-Aldosterone System Blockers and the Risk of Covid-19. N Engl J Med 2020; 382:2431-40. DOI: 10.1056/NEJMoa2006923

11. Chen D, Li X, Song Q, et al. Assessment of hypokalemia and clinical characteristics in patients with coronavirus disease 2019 in Wenzhou, china. JAMA network open. 2020;3:e2011122

12. Wilcox CS, Bertram Pitt B. Is spironolactone the preferred renin-angiotensin-aldosterone inhibitor for protection against COVID-19? J Cardiovasc Pharmacol. 2020 Dec 4; 77(3):323-331. DOI: 10.1097/FJC.0000000000000960

Facultad de Medicina. Universidad Peruana Cayetano Heredia.

Profesor principal.

Especialista en Nefrología. 